\title{
Pregnancy and the changing pattern of rheumatic heart disease
}

\author{
Paul Szekely, Richard Turner, and Linton Snaith \\ From the Cardiovascular Department and Department of Obstetrics, Newcastle General Hospital, Newcastle \\ upon Tyne; and the University Department of Medicine, Western General Hospital, Edinburgh
}

The clinical aspects of rheumatic heart disease in relation to pregnancy are reviewed in a combined series of patients chiefly from the Newcastle General Hospital studied over a period of 28 years, and from the Western General Hospital in Edinburgh studied over 25 years.

In both centres, since about 1960, there has been a progressive decrease in the number of patients found in antenatal clinics to have rheumatic heart disease, and also in the severity of this condition. There has also been a significant fall in the incidence of major complications, such as pulmonary oedema, right heart failure, and atrial fibrillation which formerly were often encountered.

In addition to the changes in the natural course of the disease, improved medical management of the more severe cases, together with the introduction of cardiac surgery, has been responsible for a much more favourable course in the pregnant patient.

The disadvantages and potential dangers of the New York Heart Association classification are emphasized and illustrated.

The risks of valvotomy during pregnancy are no greater than in cases of comparable severity in the nonpregnant state. Subsequent close medical supervision is important because complications may still occur later in pregnancy. Likewise should pregnancy occur after successful valvotomy, close observation throughout is essential.

Current concepts of medical, surgical, and obstetric management are outlined.

Routine medical examinations at about IO, I5, and 20 years of age with appropriate management would render pregnancy virtually safe for every patient with rheumatic heart disease.

As judged by the number of new patients found at present to have rheumatic heart disease when examined in antenatal clinics in Newcastle, Edinburgh, and in three other regions of Scotland (Szekely, 1968; Turner, 1968b; R. W. D. Turner and N. M. B. Dean, 1969, unpublished data), and by the decreasing frequency of serious complications during pregnancy such as pulmonary oedema, right heart failure, and atrial fibrillation, the prevalence and the severity of rheumatic heart disease have declined in recent years. A similar trend has recently been reported from London (Barnes, 1970). A recent inquiry carried out by one of us regarding the number of first mitral valvotomies performed anually since its introduction in 18 centres of cardiac surgery in Britain also confirms the clinical impression of a continuing decline in the incidence and severity of rheumatic heart disease in this country (R. W. D. Received II June 1973.
Turner and N. M. B. Dean, 1969, unpublished data). These facts reflect the favourable change which has taken place in the past two decades in the prevalence and in the severity of acute rheumatic fever in the Western hemisphere (Bland, 1960; Massell, Amezcua, and Pelargonio, 1964; World Health Organization, 1966; Scottish Health Service Council, 1967; Szekely, I968; Perry, 1969). However, this favourable trend is not universal as it does not apply to countries with less satisfactory socioeconomic conditions.

Despite these favourable changes rheumatic heart disease is still sufficiently prevalent to constitute one of the potentially most serious medical risks encountered in pregnancy. Also because of the steep decline in maternal deaths from other causes, and in particular from infection, haemorrhage, and toxaemia, heart disease has proportionately come to assume a more prominent position as a cause of 
TABLE I Incidence of rheumatic heart disease in pregnancy

\begin{tabular}{|c|c|c|c|c|c|c|c|c|}
\hline \multirow{3}{*}{ Years } & \multicolumn{3}{|l|}{ Newcastle } & \multicolumn{3}{|l|}{ Edinburgh } & \multicolumn{2}{|l|}{ Total } \\
\hline & \multirow[t]{2}{*}{$\begin{array}{l}\text { No. of all } \\
\text { pregnancies }\end{array}$} & \multicolumn{2}{|c|}{$\begin{array}{l}\text { Pregnancies } \\
\text { complicated by } \\
\text { rheumatic heart } \\
\text { disease }\end{array}$} & \multirow[t]{2}{*}{$\begin{array}{l}\text { No. of all } \\
\text { pregnancies }\end{array}$} & \multicolumn{2}{|c|}{$\begin{array}{l}\text { Pregnancies } \\
\text { complicated by } \\
\text { rheumatic heart } \\
\text { disease }\end{array}$} & \multirow[t]{2}{*}{$\begin{array}{l}\text { No. of all } \\
\text { pregnancies }\end{array}$} & \multirow{2}{*}{$\begin{array}{l}\text { Pregnancies } \\
\text { complicated } \\
\text { by rheumatic } \\
\text { heart disease } \\
\%\end{array}$} \\
\hline & & No. & $\%$ & & No. & $\%$ & & \\
\hline I942-I947 & 5617 & 193 & 3.5 & & & & 5617 & 3.5 \\
\hline $1948-1957$ & 16672 & 517 & $3 \cdot 1$ & 49915 & 845 & $1 \cdot 7$ & 66587 & $2 \cdot 0$ \\
\hline $1958-1965$ & 14912 & 235 & $I \cdot 6$ & 45287 & 827 & $1 \cdot 8$ & 60199 & $I \cdot 7$ \\
\hline $1966-1969$ & 9875 & 103 & $\mathbf{I} \cdot \mathbf{I}$ & $2555^{1}$ & 136 & 0.5 & 35426 & 0.7 \\
\hline Total & 47076 & 1048 & $2 \cdot 2$ & 120753 & 1808 & $1 \cdot 5$ & 167829 & $I \cdot 7$ \\
\hline
\end{tabular}

maternal morbidity and mortality. Every maternal death from rheumatic heart disease can be regarded as potentially preventable. Appropriate prophylactic and therapeutic management of rheumatic carditis from the onset of this disease and the early discovery of insidious asymptomatic but severe mitral stenosis by routine medical examination at school leaving age and again at the age of about 20 would render pregnancy virtually safe in every patient with rheumatic heart disease.

In view of this situation and of the changes in the course of severe valve lesion brought about by the introduction of cardiac surgery, and in the light of a better understanding of the haemodynamics of rheumatic heart disease and of the circulatory changes of pregnancy made possible by improved laboratory methods of investigation, a reappraisal of rheumatic heart disease in relation to pregnancy is warranted. It is the purpose of this paper to present data obtained in two medical centres over a 28-year period from 1942 to 1969 in a large number of patients, many of whom have been also observed in the years preceding pregnancy. In this analysis, an attempt has been made to emphasize the changing clinical pattern of rheumatic heart disease and to put the present situation in statistical perspective.

\section{Subjects}

The data compiled at the Newcastle General Hospital are based on 1048 consecutive pregnancies in 723 patients with rheumatic heart disease studied between 1942 and 1969. These patients have been closely followed by the same obervers for 7456 patient-years with an average period of more than ro years. The dominant valve lesion was mitral stenosis in 90 per cent of the cases, mitral regurgitation in 6.6 per cent, aortic regurgitation in 2.5 per cent, and aortic stenosis in I per cent.

The Edinburgh material which is particularly considered in relation to surgical treatment carried out before or during pregnancy, and to maternal mortality, comprises a total of 1808 cardiac pregnancies (Simpson Memorial Maternity Pavilion Reports, 1962-69; Turner and Marquis, 1965; Turner, 1968b; Marquis, 1969). The distribution of valve defects was similar to that in the Newcastle series. In all respects the trend of experience has been the same in both centres.

There has been a gradual fall in the incidence of rheumatic heart disease as seen in Table $\mathrm{r}$.

\section{Clinical observations and results}

The principal complications of rheumatic heart disease encountered during pregnancy, all of which have become much less frequent in recent years, were pulmonary congestion, pulmonary oedema, right heart failure, dysrhythmias, and embolism. The incidence of these complications in the Newcastle series is analysed in detail (Table 2).

\section{Heart failure}

It is appreciated that at the present time there is no agreed definition as to what constitutes heart failure. In mitral stenosis, which is the most frequent valve defect found in pregnancy, pulmonary congestion and oedema are not primarily caused by myocardial failure, but by mechnical obstruction at the mitral valve with consequent increase in left atrial and pulmonary venous pressures. Also the conventional manifestations of right heart failure, namely raised jugular venous pressure, engorgement of the liver, and peripheral oedema, are closely related to fluid retention which is also determined by a fall in cardiac output, so-called 'forward' failure with consequent renal retention of salt and water. However, in this paper it is not our purpose to discuss the pathogenesis of the clinical manifestations of heart failure in general, but it is necessary to ensure clarity as to what is being described when using the familiar subdivision of heart failure into pulmonary congestion, pulmonary oedema, and right heart failure. Such a subdivision proved help- 
TABLE 2 Frequency of acute pulmonary oedema, right heart failure, atrial fibrillation, and systemic embolism in pregnancy complicated by rheumatic heart disease (Newcastle)

\begin{tabular}{|c|c|c|c|c|c|c|c|c|c|}
\hline \multirow[t]{2}{*}{ Years } & \multirow{2}{*}{$\begin{array}{l}\text { No. of } \\
\text { pregnancies } \\
\text { complicated by } \\
\text { rheumatic heart } \\
\text { disease }\end{array}$} & \multicolumn{2}{|c|}{ Pulmonary oedema } & \multicolumn{2}{|c|}{ Right heart failure } & \multicolumn{2}{|c|}{ Atrial fibrillation } & \multicolumn{2}{|c|}{ Systemic embolism } \\
\hline & & $\begin{array}{l}\text { No. of } \\
\text { pregnancies }\end{array}$ & $\%$ & $\begin{array}{l}\text { No. of } \\
\text { pregnancies }\end{array}$ & $\%$ & $\begin{array}{l}\text { No. of } \\
\text { pregnancies }\end{array}$ & $\%$ & $\begin{array}{l}\text { No. of } \\
\text { pregnancies }\end{array}$ & $\%$ \\
\hline $\begin{array}{l}\text { I942-195I } \\
\text { (pre-valvotomy era) }\end{array}$ & 413 & I0 & $2 \cdot 5$ & 14 & 3.4 & 27 & $6 \cdot 5$ & 7 & $\mathrm{I} \cdot 7$ \\
\hline $1952-1961$ & 432 & 10 & $2 \cdot 3$ & 6 & $\mathrm{I} \cdot 4$ & 36 & $8 \cdot 4$ & 7 & $I \cdot 6$ \\
\hline $1962-1969$ & 203 & 0 & 0 & 0 & 0 & 6 & $3 \cdot 0$ & $\mathbf{I}$ & 0.5 \\
\hline Total & 1048 & 20 & $2 \cdot 0$ & 20 & $2 \cdot 0$ & 69 & 6.8 & 15 & $1 \cdot 4$ \\
\hline
\end{tabular}

TABLE 3 Heart failure in relation to cardiac rhythm in pregnancy complicated by rheumatic heart disease (Newcastle)

\begin{tabular}{|c|c|c|c|c|c|c|c|}
\hline \multirow{2}{*}{\multicolumn{2}{|c|}{ Cardiac rhythm }} & \multirow[t]{2}{*}{$\begin{array}{l}\text { No. of } \\
\text { pregnancies }\end{array}$} & \multirow[t]{2}{*}{$\begin{array}{l}\text { Pulmonary } \\
\text { congestion }\end{array}$} & \multirow[t]{2}{*}{$\begin{array}{l}\text { Acute pulmonary } \\
\text { oedema }\end{array}$} & \multirow[t]{2}{*}{$\begin{array}{l}\text { Right heart } \\
\text { failure }\end{array}$} & \multicolumn{2}{|c|}{$\begin{array}{l}\text { All three types of } \\
\text { heart failure }\end{array}$} \\
\hline & & & & & & No. & $\%$ \\
\hline \multirow{2}{*}{\multicolumn{2}{|c|}{$\begin{array}{l}\text { Sinus rhythm throughout } \\
\text { Paroxysmal atrial tachycardia }\end{array}$}} & 94I & 158 & 15 & I I & 184 & 19.5 \\
\hline & & 38 & 5 & 2 & 0 & 7 & $18 \cdot 5$ \\
\hline \multirow{3}{*}{$\begin{array}{l}\text { Paroxysmal or } \\
\text { established } \\
\text { atrial } \\
\text { fibrillation }\end{array}$} & $\begin{array}{l}\text { Onset before } \\
\text { pregnancy } \\
\text { Onset in }\end{array}$ & 36 & 4 & $\mathbf{I}$ & 3 & 8 & $22 \cdot 0$ \\
\hline & pregnancy or & 33 & 13 & 2 & 6 & 21 & $63 \cdot 0$ \\
\hline & Total & $\overline{69}$ & 17 & 3 & 9 & 29 & $\overline{42 \cdot 0}$ \\
\hline \multicolumn{2}{|l|}{ Total } & 1048 & 180 & 20 & 20 & 220 & $22 \cdot 0$ \\
\hline
\end{tabular}

ful from the point of view of management and prognosis.

Pulmonary congestion Criteria for the diagnosis of pulmonary congestion were a history of undue dyspnoea with persistent basal crepitations and/or radiographic signs of interstitial oedema.

Pulmonary congestion was observed in 180 (18\% of all pregnancies and in $82 \%$ of those with one of the three types of heart failure (Table 3)). In about 6 per cent of the cases pulmonary congestion occurred in the puerperium. Pure or dominant mitral stenosis was present in 176 instances and mitral regurgitation was the dominant lesion in 4 cases.

The incidence of pulmonary congestion increased with age from II per cent in patients under 20 years to 26 per cent in those 30 years or older.

There was also a significant rise in its incidence with increase in cardiac size from 16 per cent in patients with little or no cardiac enlargement (cardiothoracic ratio $<55 \%$ ) to 35 per cent in patients with great cardiac enlargement (CTR $>60 \%$ ).
The incidence was 17 per cent in those in sinus rhythm throughout, 13 per cent in those who experienced episodes of atrial tachycardia, and 25 per cent in those with transient or established atrial fibrillation. In the atrial fibrillation group, pulmonary congestion was more than three times as frequent in those in whom the dysrhythmia developed during pregnancy or in the puerperium than in those in whom it had been previously present and the ventricular rate controlled by digitalis before the onset of pregnancy (Table 3).

Pulmonary oedema Acute pulmonary oedema was diagnosed by the rapid onset of dyspnoea necessitating the upright position, associated with cough and often the production of frothy sputum with or without blood staining, and by evidence of diffuse pulmonary congestion. The difference between pulmonary congestion and acute pulmonary oedema is only one of degree, but clinically the two conditions are readily distinguishable.

Pulmonary oedema occurred in 20 of the 1048 pregnancies $(2 \%)$, and in 9 per cent of those with 
one of the three types of heart failure (Table 3). These 20 pregnancies occurred in 18 patients who between them experienced a total of 25 attacks. Twenty attacks occurred during pregnancy and 5 in the puerperium. Sixteen of the 18 patients had pure mitral stenosis. In 2, the dominant lesion was aortic regurgitation, but there were important associated disorders in both cases: hypertensive toxaemia and hemichorea, respectively.

Twenty-two of the attacks occurred in patients under the age of 30 and 3 in those over the age of 30. This age distribution is in sharp contrast to that found in the two other types of heart failure which occurred more frequently in patients over 30.

In all patients the cardiothoracic ratio was under 60 per cent and there was only a marginal increase in the incidence of pulmonary oedema with increase in heart size. The fact that no episode of pulmonary oedema occurred in patients with a cardiothoracic ratio over 60 per cent is again in sharp contrast to pulmonary congestion and right heart failure.

In 4 patients pulmonary oedema developed with the onset of atrial fibrillation or atrial tachycardia. Another patient had long-established atrial fibrillation. The remaining 20 episodes occurred in sinus rhythm. The precipitating factors which were assumed to be operative are listed in Table 4. In 6 instances no particular event was observed immediately before the attack, but since emotional upset is known to be often responsible this may have been a cause.

The incidence of pulmonary oedema in successive periods since 1942 is shown in Table 2 . It is noteworthy that no episodes were observed after 1960, a fact that can be attributed to the introduction of

TABLE 4 Acute pulmonary oedema in pregnancy complicated by rheumatic heart disease (Newcastle). Precipitating factors in 25 attacks occuring in 29 pregnancies in 18 patients

\begin{tabular}{ll}
\hline $\begin{array}{l}\text { Conditions immediately preceding onset of pulmonary } \\
\text { oedema }\end{array}$ & $\begin{array}{l}\text { No. of } \\
\text { attacks }\end{array}$ \\
\hline Ectopic tachycardia & 4 \\
Respiratory infection & 4 \\
Physical effort & 3 \\
Cerebral embolism & I \\
Pulmonary embolism & I \\
Plasma transfusion & I \\
Toxaemia of pregnancy & 2 \\
Hemichorea & I \\
Emotional upset & I \\
Miscarriage & I \\
Nothing noticeable & 6 \\
\hline
\end{tabular}

mitral valvotomy and also to the natural decrease in the severity of rheumatic heart disease.

Right heart failure A diagnosis of right heart failure was made when in addition to pulmonary congestion the jugular venous pressure was raised and peripheral oedema developed in the absence of other obvious causes such as severe anaemia or toxaemia of pregnancy. In these cases, pulmonary congestion was followed by what we have termed right heart failure without the clinical picture of acute pulmonary oedema. In these patients the heart was nearly always grossly enlarged but the valve defects were not necessarily severe.

Right heart failure thus defined occurred in 20 pregnancies, constituting 2 per cent of the whole series and 9 per cent of those with one of the three types of heart failure (Table 2).

All 20 patients had dominant mitral stenosis : pure stenosis in 16 , and slight mitral regurgitation as well in 4.

The incidence of right heart failure increased with advancing age, reaching to per cent in patients of 40 years or over. It was also more frequent when the heart was greatly enlarged, the incidence being only 0.25 per cent in patients with slight cardiac enlargement and 15 per cent in those with cardiothoracic ratio over 60 per cent.

Right heart failure occurred in II (I\%) of the pregnancies in the sinus rhythm group, and in 9 (13\%) of those complicated by transient or established atrial fibrillation. In the latter group it occurred twice as often in patients in whom atrial fibrillation developed during pregnancy or in the puerperium than in those in whom it had been previously present and the ventricular rate controlled (Table 3).

The incidence of right heart failure in successive periods since 1942 is shown in Table 2. It is noteworthy that this complication has not been seen since 1960, which again reflects the decreasing severity of myocardial damage as judged by the degree of cardiac enlargement and/or atrial fibrillation.

\section{Distribution of heart failure throughout preg- nancy}

The data summarized in Table 5 clearly show that the incidence of all three types of heart failure increases as pregnancy advances. No less than II (44 per cent) of the 25 attacks of acute pulmonary oedema observed in 20 pregnancies occurred during the last four weeks, and 5 of the attacks $(20 \%)$ in the puerperium. However, on only 2 occasions did the attacks appear first in the puerperium, the remaining patients having had previous attacks. 
TABLE 5 Onset of heart failure in pregnancy complicated by rheumatic heart disease (Nervcastle)

\begin{tabular}{|c|c|c|c|c|}
\hline \multirow{2}{*}{$\begin{array}{l}\text { Weeks of } \\
\text { pregnancy }\end{array}$} & \multicolumn{3}{|c|}{ No. of pregnancies } & \multirow{2}{*}{$\begin{array}{l}\text { Percentage distribution } \\
\text { of heart failure }\end{array}$} \\
\hline & $\begin{array}{l}\text { Pulmonary } \\
\text { congestion }\end{array}$ & $\begin{array}{l}\text { Acute pulmonary } \\
\text { oedema }\end{array}$ & $\begin{array}{l}\text { Right heart } \\
\text { failure }\end{array}$ & \\
\hline-15 & 10 & 0 & 0 & $\begin{array}{l}4.5 \\
8.5\end{array}$ \\
\hline $16-20$ & 18 & $\mathbf{I}$ & 0 & $8 \cdot 5$ \\
\hline $21-25$ & 22 & 3 & $\mathbf{I}$ & $12 \cdot 0$ \\
\hline $26-30$ & 32 & 4 & 2 & $17 \cdot 0$ \\
\hline $3 I-35$ & 36 & I & 5 & 18.5 \\
\hline $36-40$ & 51 & II I & 9 & $31 \cdot 0$ \\
\hline Puerperium & II & 5 & 3 & 8.5 \\
\hline
\end{tabular}

Three pregnancies were complicated by two and one pregnancy by three attacks of pulmonary oedema.

\section{Cardiac dysrhythmias}

Atrial and ventricular extrasystoles, sometimes as a bigeminal rhythm, are commonly encountered in pregnancy and are as a rule of no significance. Paroxysmal or established atrial fibrillation and atrial tachycardia are not infrequent, but ventricular tachycardia is rare (Szekely and Snaith, 1953, I96I ; Pine, Fox, and Shook, I965).

Atrial fibrillation Transient or permanent atrial fibrillation complicated 69 pregnancies in 59 patients between the ages of 18 and 44, with an average age of 32 years. In 36 instances it was either known with certainty or assumed on reasonable grounds that the dysrhythmia had been present before pregnancy. In 23 instances it appeared during pregnancy and in to in the puerperium.

Mitral valve disease was present in 56 patients: pure stenosis in 46 , and slight regurgitation as well in Io. Three patients had dominant mitral regurgitation. Mitral valve disease was associated with aortic regurgitation in 17 cases but in no case was the aortic regurgitation the dominant lesion.

Thirteen patients had slight cardiac enlargement (CTR $<55 \%$ ), 36 moderate enlargement (CTR $55-60 \%)$, and to patients considerable enlargement (CTR $>60 \%$ ).

Heart failure occurred in 29 of the 69 pregnancies $(42 \%)$, though atrial fibrillation was not necessarily the immediate precipitating factor. When established atrial fibrillation had been present before pregnancy, the three types of heart failure occurred in 8 out of 36 pregnancies ( $22 \%)$. When the dysrhythmia first developed during pregnancy or in the puerperium heart failure occurred in a much higher proportion (63\%, Table 3$)$.

The incidence of atrial fibrillation in successive periods since 1942 is shown in Table 2. It is nowadays much less frequently encountered in pregnancy.
Atrial flutter Atrial flutter is uncommon during pregnancy and was only encountered twice. Its significance is similar to that of atrial fibrillation.

Atrial tachycardia A diagnosis of paroxysmal atrial tachycardia was made in 28 patients with rheumatic heart disease between the ages of $2 I$ and 41 who had 52 documented attacks in 38 pregnancies. Forty-four attacks occurred during pregnancy and 8 in the puerperium. Twenty-one patients had attacks only in pregnancy, mainly during the last trimester, 3 only in the puerperium, and 4 in both pregnancy and the puerperium.

Moderate to severe pure or dominant mitral stenosis was present in 25 patients and dominant mitral regurgitation in 3 patients. Associated aortic regurgitation was found in 6 patients but in no case was it the dominant lesion.

In I6 patients the first attack occurred during pregnancy or in the puerperium and 12 of these did not have attacks at any other time. The other 4 as well as the remaining 12 patients continued to have occasional attacks after pregnancy. Eight attacks lasted between 6 and 72 hours, and 5 of these precipitated pulmonary congestion and 2 acute pulmonary congestion and 2 acute pulmonary oedema. All other attacks lasted from 30 to 90 minutes only and were not followed by heart failure.

\section{Systemic embolism}

Fifteen episodes of systemic embolism were observed in 15 patients $(1.5 \%)$. Eleven episodes occurred during pregnancy and 4 in the puerperium. Eight patients were in sinus rhythm and 7 had proven paroxysmal or established atrial fibrillation. In 6 of the 7 patients with atrial fibrillation embolism occurred between less than 24 hours and 9 days after the onset of the ectopic tachycardia. In one patient atrial fibrillation had been present before pregnancy. 
TABLE 6 Mitral valvotomy during pregnancy

\begin{tabular}{|c|c|c|c|}
\hline & Newcastle & Edinburgh & Total \\
\hline $\begin{array}{l}\text { No. of patients } \\
\text { Age at operation }\end{array}$ & 25 & 44 & 69 \\
\hline$<30$ years & I4 & 28 & 42 \\
\hline$>30$ years & I I & 16 & 27 \\
\hline \multicolumn{4}{|l|}{ Time of operation } \\
\hline Ist trimester & 3 & 7 & Io \\
\hline 2nd trimester & IO & 30 & 40 \\
\hline 3rd trimester & 10 & 7 & 17 \\
\hline Puerperium & 2 & 0 & 2 \\
\hline \multicolumn{4}{|l|}{ Degree of stenosis } \\
\hline Severe & I8 & $4 I$ & 59 \\
\hline Moderate & 7 & 3 & 10 \\
\hline Operative deaths & $\mathbf{I}$ & I & 2 \\
\hline \multicolumn{4}{|l|}{ Postoperative complications } \\
\hline Heart failure & 2 & 2 & 4 \\
\hline Transient or permanent atrial fibrillation & 8 & 0 & 8 \\
\hline Systemic embolism & 2 & $\circ$ & 2 \\
\hline
\end{tabular}

The dominant valve lesion was mitral stenosis in all cases: pure stenosis in $12(80 \%)$ and slight regurgitation as well in $3(20 \%)$.

\section{Pulmonary embolism}

Pulmonary embolism occurred in 20 patients ( $2 \%)$. Nine were in sinus rhythm and II had paroxysmal or established atrial fibrillation. Four patients in the latter group also had systolic embolism. Sixteen episodes occurred during pregnancy and 4 in the puerperium.

Pure or dominant mitral stenosis was present in I8 patients, and dominant mitral regurgitation in 2 patients.

Only 4 of the 20 patients had clinically overt deep vein thrombosis. Haemoptysis was observed in 6 of the 20 cases. None of the patients was on anticoagulant treatment at the onset of pulmonary embolism. The 4 patients with overt phlebothrombosis were observed in the pre-anticoagulant era.

In one patient pulmonary embolism followed termination of pregnancy and in 2 delivery by caeserian section.

In 1942, a 24-year-old woman who developed atrial fibrillation Io days after an uneventful delivery, and a popliteal embolism 9 days later, died on the 23rd postpartum day exhibiting the clinical signs of massive pulmonary embolism. There was no evidence of overt phlebothrombosis. Permission for necropsy could not be obtained.

\section{Cardiac surgery in relation to pregnancy}

Mitral valvotomy during pregnancy

In the combined experience of the Newcastle General Hospital, the Western General Hospital, and the Royal Infirmary in Edinburgh mitral valvotomy has been carried out in 69 patients since 195I (Table 6). Ten patients had their operation in the first, 40 in the second, and 17 in the third trimester, and 2 in the puerperium.

The main postoperative complications were heart failure and atrial fibrillation. Heart failure developed in 4 of the 69 patients: 2 of these had previous right heart failure suggesting considerable myocardial damage. Postoperative atrial fibrillation developed in 8 patients, but sinus rhythm was restored in 6 of them.

There were 2 operative deaths: one from traumatic mitral regurgitation (before the introduction of open heart surgery) and the other after an emergency mitral valvotomy for uncontrolled pulmonary oedema.

There were 2 spontaneous abortions and 6 perinatal deaths.

In the first 15 years after the introduction of mitral valvotomy, 64 operations were considered necessary in pregnancy. Between 1966 and 1969, using the same criteria for operative treatment, there have only been 5 such cases.

\section{Pregnancy after mitral valvotomy}

In the combined series from the three hospitals, I6I patients experienced 210 pregnancies after mitral valvotomy. Thirty-seven patients developed undue dyspnoea or cardiac failure at some stage of pregnancy.

There were 3 maternal deaths: I from acute pulmonary oedema in a 27-year-old woman who had a closed mitral valvotomy in a previous pregnancy 3 years earlier, and 2 patients died from infective endocarditis. 
TABLE 7 Causes of maternal death in pregnancy complicated by rheumatic heart disease

\begin{tabular}{|c|c|c|c|}
\hline Cause of death & Newcastle & Edinburgh & Total \\
\hline Pulmonary oedema & 6 & 7 & 13 \\
\hline Right heart failure & I & 0 & $\mathbf{I}$ \\
\hline Pulmonary embolism & $\mathbf{I}$ & 2 & 3 \\
\hline Bacterial endocarditis & 0 & 2 & 2 \\
\hline Acute rheumatic carditis & $\mathbf{I}$ & $\mathbf{I}$ & 2 \\
\hline Acute circulatory failure & $\mathbf{I}$ & $\mathbf{I}$ & 2 \\
\hline Traumatic (operative) mitral regurgitation & o & $\mathbf{I}$ & $\mathbf{I}$ \\
\hline Obstruction of tricuspid orifice by aneurysm of atrial septum & $\mathbf{I}$ & o & $\mathbf{I}$ \\
\hline Non-cardiac death & $\mathbf{I}$ & 0 & I \\
\hline Total & 12 & 14 & 26 \\
\hline
\end{tabular}

\section{Pregnancy after valve repair or replacement}

At the Edinburgh Western General Hospital 2 patients had pregnancies after mitral valve repair for mitral regurgitation, 3 after mitral, and I after aortic valve replacement by Starr-Edwards prosthesis. At the Newcastle General Hospital 2 patients became pregnant after mitral valve repair, and I pregnancy was observed after mitral valve replacement by Starr-Edwards prosthesis. All 9 pregnancies were uncomplicated and there was no foetal loss.

The 5 patients with valve replacement continued with oral anticoagulant treatment until the onset of labour and resumed it within 24 hours after delivery.

\section{Maternal mortality}

In the Newcastle series there were I2 deaths, but none since 1960 (Table 7). In 6 patients the cause of death was acute pulmonary oedema, 3 of which occurred in the prevalvotomy era. The other 3 deaths caused by pulmonary oedema occurred, respectively, in a patient who was admitted to hospital moribund and died within an hour, in another patient who had closed mitral valvotomy in a previous pregnancy for pulmonary oedema and died in a subsequent pregnancy before arrangements for a second mitral valvotomy could have been completed, and in a further patient who was actually operated on at 38 weeks, but died 18 hours after mitral valvotomy without regaining consciousness. Two other deaths which occurred in the prevalvotomy era and could be regarded today as potentially preventable were due, respectively, to progressive right heart failure and to peripheral circulatory failure associated with profuse haemoptysis. Rheumatic carditis and pulmonary embolism were each responsible for one death. Another patient died suddenly in the puerperium and the necropsy showed obstruction of the tricuspid orifice by a tumour-like structure which proved to be an aneurysm of the atrial septum filled with blood clots. In the twelfth patient the cause of death was noncardiac.

In the Edinburgh series there were 14 deaths from rheumatic heart disease, but none since 1960 . Before mitral valvotomy became established 5 patients with severe mitral stenosis died from pulmonary oedema. On the other hand, between 1952 and 1960 only 2 patients died from pulmonary oedema and neither had been seen in an antenatal clinic. Two of the other deaths were from pulmonary embolism, 2 from infective endocarditis, I from sudden circulatory failure in a patient with a very large heart, I from acute rheumatic carditis, and I from traumatic (operative) mitral regurgitation.

\section{Foetal mortality}

The perinatal mortality rate as observed at the Newcastle General Hospital has been gradually falling over the whole period from 8.8 per cent (1942I95I) to under 5 per cent (196I-I969). It is, however, still higher than the current general perinatal mortality rate which is less than 3 per cent.

\section{Discussion}

The data presented here cover a period of 28 years between 1942 and 1969 and provide a spectrum of the changing clinical pattern of rheumatic heart disease as observed in the child-bearing age and in the pregnant woman. They reflect a gradual decline in the incidence of rheumatic heart disease and also a favourable change in the severity of the disease. This trend has continued since 1969 .

\section{Principles of antenatal care}

The clinical course of rheumatic heart disease which is in the majority of cases well established before the child-bearing age may be temporarily influenced by pregnancy. The purpose of cardiac antenatal care is the detection of the nature of the cardiac abnor- 
mality, the precise assessment of its severity, and the introduction of appropriate measures aimed at the prevention of complications.

Any form of purely functional grading, such as that recommended by the New York Heart Association which is still widely used, can in our opinion be misleading, potentially dangerous, and should therefore be abandoned. We have already defended this point of view in several discussions (Turner and Marquis, 1965; Turner, 1968a; Szekely and Turner, 1968). It is usually assumed that symptoms necessarily reflect the severity of the underlying heart disease. However, experience has shown that this is not the case. It is true that when a functional classification has been used, published figures have shown a comparatively low maternal mortality rate in grades I and II. However, this is so because in the great majority of cases the rhuematic valve defect is not severe. It is equally true that the majority of maternal deaths during pregnancy occur in patients who when first seen were placed in functional grades I or II. In particular, a patient with severe mitral stenosis but good myocardium and little or no cardiac enlargement can be practically symptom free at the beginning of pregnancy and yet develop later fatal pulmonary oedema. We believe, therefore, that cardiac antenatal care should be governed by an assessment based essentially on objective findings, with a view to establishing the severity of the lesion and thus the potential risk of pregnancy and the need for special medical or surgical treatment.

Complications The most important complications encountered during pregnancy included acute pulmonary oedema, right heart failure, atrial fibrillation, and embolism. Formerly these complications were responsible for serious maternal morbidity and mortality, but they have gradually become less frequent. The steady decrease in maternal mortality from cardiac causes is well documented (Gilchrist, 1963; Department of Health and Social Security, 1968). Important factors which have been responsible for this decrease are improved medical care during pregnancy and during the years preceding the childbearing age, including antistreptococcal prophylaxis, surgical relief of severe mitral valve obstruction, and also the natural decline in the severity of rheumatic heart disease.

Despite this favourable trend, serious and potentially dangerous complications may still occur. Thus, the report on confidential inquiries into maternal deaths in England and Wales (Department of Health and Social Security, 1968) lists 43 deaths from acquired heart disease between 1964 and 1966, 23 of which were rheumatic in origin. In the last report covering the period 1967 to 1969 there were I4 deaths from rheumatic heart disease.

The pattern of heart failure during pregnancy has undergone a gradual change during the past 20 years. Gilchrist (1963) reported that between 1928 and 1947 right heart failure accounted for 6r per cent and acute pulmonary oedema for 13 per cent of cardiac deaths, whereas between 1948 and 1960 the corresponding figures were 8 per cent and 67 per cent, respectively. This trend has continued.

Acute pulmonary oedema, though much less common than previously, is today the most important single cardiac cause of maternal mortality. A woman with even moderately severe mitral stenosis may develop pulmonary oedema during pregnancy because of the increase in blood volume, in cardiac output, and in heart rate, accompanied by an increase in left atrial, pulmonary venous, and pulmonary capillary pressures (Burwell and Metcalfe, 1958). In this way an anatomically moderate stenosis can be transformed into a functionally severe one. It is helpful to recognize the type of patient who is especially susceptible to pulmonary oedema. She is likely to be under the age of 30 with few if any previous symptoms, with clinical signs of moderate to severe mitral stenosis, and, as a rule, with only slight cardiac enlargement and normal sinus rhythm. In assessing the risks of pregnancy in this type of patient it is essential to appreciate that the functional capacity of the heart before pregnancy or at its onset is no measure of the risk of acute pulmonary oedema during pregnancy. It also appears that the combination of mitral stenosis or aortic regurgitation and of toxaemia of pregnancy is unfavourable as this association potentiates the tendency to pulmonary oedema.

Right heart failure has in our experience virtually disappeared in recent years. It used to be observed as a rule in older patients with larger hearts, considerable myocardial damage, and symptoms before pregnancy. These observations are similar to those reported earlier by Jones (1959).

The available data show that heart failure can occur at any stage of pregnancy and that its incidence increases as pregnancy progresses. This trend is maintained until term. These long-appreciated clinical observations have now found their explanation in the recent findings that the cardiac output does not fall as previously thought until after delivery. When the cardiac output is measured in the lateral recumbent position a fall towards the end of pregnancy is not observed (Lees et al., 1967; Kerr, 1968; Mulholland and Boyle, 1968; Ueland et al., 1969; Hytten and Leitch, 197I). The decrease in cardiac output previously described in late pregnancy in the supine position is due to the reduction 
in venous return brought about by compression of the inferior vena cava by the gravid uterus. The early puerperium is also a critical period, probably because of the redistribution of the blood volume which occurs at this time and results in a further transient rise in cardiac output.

Uncontrolled atrial fibrillation carries the risk of precipitating pulmonary congestion or oedema and also systemic embolism (Szekely and Snaith, 196I). In our experience, atrial fibrillation is a less serious complication when established before pregnancy and the heart rate already well controlled with digitalis than when it develops during pregnancy. Patients who first develop atrial fibrillation during pregnancy do so as a rule after the fourth month at a time when the blood volume is already increased almost to its maximum. It is therefore possible that the increase in circulating blood volume in a patient with severe rheumatic heart disease may be an important factor in determining the onset of atrial fibrillation. Another possible factor might be rheumatic activity with carditis, a raised antistreptolysin titre having been found not uncommonly, but the evidence for this is conflicting and in the individual patient the diagnosis of rheumatic activity may be difficult or impossible to make. In any event, atrial fibrillation reflects significant myocardial damage, especially if associated with more than slight cardiac enlargement. Atrial tachycardia can also precipitate pulmonary congestion or oedema, especially if it lasts for several hours, and should therefore be terminated as early as possible.

In our series, all 15 patients with systemic embolism had dominant mitral stenosis: 8 were in sinus rhythm; 7 had atrial fibrillation, and in 6 of these embolism occurred between $I$ and 9 days after the onset of the dysrhythmia. This feature reflects the general tendency for embolism to occur shortly after the onset of atrial fibrillation.

The fatal episode of massive pulmonary embolism we observed occurred in the pre-anticoagulant era. However, in this case there were no clinical warning signs which are often present preceding a fatal episode (Marquis, 1966), except that the patient developed atrial fibrillation 13 days earlier and systemic embolism 4 days earlier. Contrary to some other series, we observed more episodes of pulmonary embolism in the antepartum period than in the puerperium. In a recent report, Henderson, Lund, and Creasman (I972) suggested that there might be a decreasing incidence of pulmonary embolism in the puerperium and a relative increase in the number of cases in the antepartum period.

\section{Current concepts of management}

(I) Medical aspects Potentially, acute pulmon- ary oedema is preventable. The recognition of early pulmonary congestion and its appropriate management constitutes an important step towards its prevention. Respiratory infection is a frequent preceding event and requires early and energetic treatment. If pulmonary congestion appears, the patient should be rested in bed and treated with digitalis and diuretics. The medical management of acute pulmonary oedema consists of the administration of morphine together with a drug aimed at preventing vomiting, oxygen, a rapidly-acting diuretic, digitalis, and assisted respiration if necessary. The patient should be nursed in a propped-up position.

Atrial fibrillation with a rapid ventricular rate requires immediate bed-rest and digitalis. Sometimes a beta-blocking agent such as practolol or oxprenolol is helpful. Owing to the potential danger of systemic embolism early after the onset of atrial fibrillation, anticoagulant treatment should be considered in selected cases, especially if significant mitral stenosis is present.

Although in a given series of cases there may be no evidence that systemic embolism in the presence of rheumatic heart disease occurs more frequently during pregnancy than in non-pregnant patients of the same age group, in our experience the risk per patient-year in the atrial fibrillation group proved to be higher in pregnancy than in the non-pregnant state. It is also noteworthy that when systemic embolism occurred in atrial fibrillation, it did so within Io days after its onset in 85 per cent of the cases. Intravascular thrombosis probably occurs more frequently in pregnancy than in the nonpregnant state (Barnes, 1970) and certain obstetric factors, such as high parity, delivery by caesarian section, and hormone-induced suppression of lactation may further increase the tendency to thromboembolism. The desirability of anticoagulant therapy in the individual patient should therefore be determined in the light of these observations. Though anticoagulant treatment carries some risk to the foetus, it is feasible and can be made safe under strict supervision and laboratory control (Turner and Kitchin, 1968; Szekely and Snaith, 1969; Barnes, 1970). Phenindione or warfarin have proved more practicable in our experience than heparin, though heparin is theoretically safer because it does not cross the placental barrier. Macdonald (1970) suggested a reasonable compromise in giving oral anticoagulants during pregnancy and replacing it by heparin shortly before the onset of labour, as transplacental transmission may be most dangerous at the time of delivery. In a recent review, Hirsh, Cade, and O'Sullivan (1970) have also stated that anticoagulant treatment can be safely carried out during pregnancy. They observed only occasional minor 
haemorrhagic episodes and no foetal or neonatal complications. If anticoagulants are used until the onset of labour it is reasonable to give vitamin $\mathrm{K}$ to the newborn (Mendelson, 1960).

The conventional antidysrhythmic agents for the abolition of atrial fibrillation or atrial tachycardia are not contraindicated in pregnancy and can be used with success (Szekely and Snaith, 1953). Direct current shock has also been safely used in pregnancy (Vogel, Pryor, and Blount, 1965; Schroeder and Harrison, 1971). The indications for these procedures are similar to those in the non-pregnant patient.

(2) Surgical aspects: (a) Closed mitral valvotomy. In general, the indications for closed mitral valvotomy during pregnancy and the operative mortality do not differ from those outside pregnancy (Logan and Turner, 1952; Szekely and Snaith, 1963; Ueland, 1965; Snaith and Szekely, 1967; Metcalfe, 1968; Turner, 1968b; Metcalfe and Ueland, 1970). However, in certain cases operative treatment appears to be more urgent than if the patient were not pregnant, and in other cases operation should be postponed until some time after delivery. As closed mitral valvotomy carries today a low operative risk, it should be carried out in the presence of pure mitral stenosis if pulmonary congestion develops with undue dyspnoea and there is no prompt response to medical management. Operative treatment should be considered during pregnancy when a reliable history of pulmonary oedema can be elicited, even if the patient is symptom free at the time of assessment, because pulmonary oedema is likely to recur. Profuse and uncontrollable haemoptysis usually associated with pulmonary hypertension and a severe degree of mitral stenosis also requires urgent valvotomy. It should be again emphasized that an anatomically moderate stenosis can be transformed into a functionally severe one by the haemodynamic changes of pregnancy.

Maternal mortality from acute pulmonary oedema can be reduced by the appropriate selection of patients for surgical treatment in whom the risk of continuing with conservative management is likely to be greater than that of operating during pregnancy. Though the operative risk is not higher during pregnancy than in the non-pregnant state, it is of course true that two lives are at stake. The incidence of traumatic mitral regurgitation should nowadays be very low and with facilities for open heart surgery immediate repair or valve replacement can be undertaken.

If mitral valvotomy is considered desirable during pregnancy, it can be performed at any stage. However, it must be emphasized that mitral valvotomy can only be regarded as a therapeutic episode in the course of rheumatic heart disease, and strict medical supervision thereafter continues to be imperative. The valve is not restored to normal, and even an apparently good valvotomy is not an absolute protection against complications in the remainder of pregnancy. Likewise, subsequent pregnancies require careful assessment and strict supervision. An increasing number of patients require further cardiac surgery in later years.

(b) Open heart surgery Pregnancy is no absolute bar to valve replacement under extracorporeal circulation. At the time of writing 22 patients have been reported who underwent open heart surgery during pregnancy, and about half of these were undertaken for mitral or aortic valve disease (Zitnik et al., 1969). The overall maternal mortality was 5 per cent in these cases, which suggests that there is no significant additional hazard in open heart surgery undertaken during pregnancy as compared with that in non-pregnant patients. However, the foetal mortality amounted to 33 per cent. A large number of patients were operated on early in pregnancy. Zitnik et al. (1969) state that open-heart surgery with extracorporeal circulation should preferably be undertaken well after the first trimester when organogenesis is completed.

Pregnancy after successful valve replacement, including the continuation of anticoagulant prophylaxis, is a manageable situation and does not constitute an unacceptable hazard (Turner and Kitchin, 1968; Szekely and Snaith, 1969; Macdonald, 1970). However, in addition to the usual potential complications, due consideration should be given to the increased risk of thromboembolism and infective endocarditis as in cases after valve replacement in general.

(3) Obstetric aspects The principles of obstetric management of patients with rheumatic heart disease do not differ greatly from those of general obstetric practice. The patients should be suitably sedated at the onset of labour and during the first stage and kept in the propped-up position as far as possible. The second stage should be shortened by forceps delivery when appropriate.

Prevailing opinion is that caesarian section should as a rule only be carried out for obstetric reasons.

Opinions are still divided on the use of ergometrine. On the whole, it should be used sparingly as it can precipitate acute pulmonary oedema in the presence of mitral stenosis.

As there is evidence that the administration of stilboestrol for the suppression of lactation after delivery is associated with an increased incidence of 
thrombophlebitis and pulmonary embolism (Daniel, Campbell, and Turnbull, 1967), it should not be used in patients with rheumatic heart disease, if at all.

We are grateful to Professor R. J. Kellar for permission to quote from the Annual Reports of the Simpson Memorial Maternity Pavilion, Edinburgh.

\section{References}

Barnes, C. G. (1970). Medical Disorders in Obstetric Practice, 3rd ed., pp. II, 26, and 214. Blackwell Scientific Publications, Oxford and Edinburgh.

Bland, E. F. (1960). Declining severity of rheumatic fever: a comparative study of the past four decades. New England Fournal of Medicine, 262, 597.

Burwell, C. S., and Metcalfe, J. (1958). Heart Disease and Pregnancy, p. 125. Little, Brown, Boston.

Daniel, D. G., Campbell, H., and Turnbull, A. C. (1967). Puerperal thromboembolism and suppression of lactation. Lancet, 2, 287.

Department of Health and Social Security (1968). Report on Confidential Enquiries into Maternal Deaths in England and Wales, 1964-66. H. M. Stationery Office, London.

Gilchrist, A. R. (1963). Cardiological problems in younger women including those of pregnancy and the puerperium. British Medical fournal, r, 209.

Henderson, S. R., Lund, C. J., and Creasman, W. T. (1972). Antepartun pulmonary embolism. American fournal of Obstetrics and Gynecology, 112, 476.

Hirsh, J., Cade, J. F., and O'Sullivan, E. F. (1970). Clinical experience with anticoagulant therapy during pregnancy. British Medical fournal, 1, 270.

Hytten, F. E., and Leitch, I. (1971). The Physiology of Human Pregnancy, 2nd ed., p. 69. Blackwell Scientific Publications, Oxford.

Jones, A. M. (1959). Heart disease in pregnancy. Proceedings of the Royal Society of Medicine, 52, 767.

Kerr, M. G. (1968). Cardiovascular dynamics in pregnancy and labour. British Medical Bulletin, 24, 19.

Lees, M. M., Scott, D. B., Kerr, M. G., and Taylor, S. H. (1967). The circulatory effects of recumbent postural change in late pregnancy. Clinical Science, 32, 453.

Logan, A., and Turner, R. W. D. (1952). Mitral valvotomy in pregnancy. Lancet, $\mathrm{I}, 1286$.

Macdonald, H. N. (1970). Pregnancy following insertion of cardiac valve prostheses: a review and further case report. fournal of Obstetrics and Gynaecology of the British Commonwealth, 77, 603.

Marquis, R. M. (I966). Pulmonary embolism and pregnancy. British Medical fournal, I, 1480 .

Marquis, R. M. (1969). Mitral disease and pregnancy. Fournal of the Royal College of Physicians of London, 3, 121.

Massell, B. F., Amezcua, F., and Pelargonio, S. (1964). Evolving picture of rheumatic fever. Fournal of the American Medical Association, 188, 287.

Mendelson, C. L. (1960). Cardiac Disease in Pregnancy, p. 67. F. A. Davis, Philadelphia.

Metcalfe, J. (1968). Rheumatic heart disease in pregnancy. Clinical Obstetrics and Gynecology, 11, roro:

Metcalfe, J., and Ueland, K. (1970). The heart and pregnancy.
In The Heart, 2nd ed., p. 1393. Ed. by J. W. Hurst and R. B. Logue. McGraw-Hill, New York.

Mulholland, H. C., and Boyle, D. McC. (I968). The effect of posture on the cardiac output during the last six weeks of pregnancy. American Heart fournal, 76, 291.

Perry, C. B. (1969). The natural history of acute rheumatism. Annals of the Rheumatic Diseases, 28, 47I.

Pine, H. L., Fox, L., and Shook, D. McK. (1965). Paroxysmal ventricular tachycardia complicating pregnancy. American fournal of Cardiology, 15, 732.

Schroeder, J. S., and Harrison, D. C. (197I). Repeated cardioversion during pregnancy. American fournal of Cardiology, 27, 445.

Scottish Health Service Council (1967). Rheumatic Fever in Scotland. H.M. Stationery Office, Edinburgh.

Simpson Memorial Maternity Pavilion, Medical and Clinical Reports (1962-1969). Royal Infirmary, Edinburgh.

Snaith, L., and Szekely, P. (1967). Cardiovascular surgery in relation to pregnancy. In Advances in Obstetrics and Gynecology, p. 220 . Ed. by S. L. Marcus and C. C. Marcus. Williams and Wilkins, Baltimore.

Szekely, P. (1968). Current incidence of rheumatic fever and the present status of prevention of rheumatic heart disease. In Proceedings of the 5th International Congress of Hygiene and Preventive Medicine, Rome, Vol. I, p. II 9.

Szekely, P., and Snaith, L. (1953). Paroxysmal tachycardia in pregnancy. British Heart fournal, 15, 195.

Szekely, P., and Snaith, L. (I96I). Atrial fibrillation and pregnancy. British Medical fournal, x, 1407.

Szekely, P., and Snaith, L. (1963). The place of cardiac surgery in the management of the pregnant woman with heart disease. Fournal of Obstetrics and Gynaecology of the British Commonwealth, 70, 69.

Szekely, P., and Snaith, L. (1969). Mitral-valve prosthesis, warfarin anticoagulation and pregnancy. Lancet, 2, 598.

Szekely, P., and Turner, R. W. D. (1968). Indications for termination of pregnancy. British Medical fournal, 2, 556.

Turner, R. W. D. (1968a). Controversial aspects of rheumatic heart disease. British Medical fournal, 2, 383.

Turner, R. W. D. (1968b). Heart disease in pregnancy. Hospital Medicine, 2, 1294.

Turner, R. W. D., and Kitchin, A. H. (1968). Pregnancy after mitral-valve prosthesis. Lancet, I, 862.

Turner, R. W. D., and Marquis, R. M. (1965). Symposium on heart disease and pregnancy. Scottish Medical fournal, ro, 47.

Ueland, K. (1965). Cardiac surgery and pregnancy. American fournal of Obstetrics and Gynecology, 92, 148.

Ueland, K., Novy, M. J., Peterson, E. N., and Metcalfe, J. (1969). Maternal cardiovascular dynamics. American fournal of Obstetrics and Gynecology, 104, 856.

Vogel, J. H. K., Pryor, R., and Blount, S. G. (1965). Directcurrent defibrillation during pregnancy. Fournal of the American Medical Association, 193, 970.

World Health Organization (1966). Prevention of rheumatic fever. World Health Organization. Technical Report Series, No. 342.

Zitnik, R. S., Brandenburg, R. O., Sheldon, R., and Wallace, R. B. (1969). Pregnancy and open-heart surgery. Circulation, 39, Suppl. I, 257.

Requests for reprints to Dr. Paul Szekely, 34 Eslington Terrace, Jesmond, Newcastle upon Tyne NE2 4 RN. 